\title{
A ÓPERA
}

\section{Veronica Stigger Instituto Superior de Educação Vera Cruz}

RESUMO: 0 texto aqui apresentado é um capítulo extra de Opisanie świata, romance que publiquei em 2013. Trata-se de um livro que nasceu intimamente relacionado com minhas pesquisas à época, sofrendo influências de várias leituras de então na sua escrita. Uma das leituras que mais me influenciou foi Maria com Marcel, de Raul Antelo, que teve um impacto imenso não só sobre as pesquisas que eu vinha desenvolvendo e que desenvolvi nos anos posteriores, mas também na construção do romance, por conta do modo como Antelo tratava alguns temas que eram caros para mim: as relações entre América e Europa e a ênfase em certos autores mais deslocados do modernismo brasileiro, como Raul Bopp, Flávio de Carvalho e a própria Maria Martins. "A ópera", portanto, quer ser, de um modo enviesado, um ensaio ficcional (uma ficção crítica) sobre o método de Raul Antelo.

PALAVRAS-CHAVE: Raul Antelo; Opisanie świata; Modernismo.

\section{THE OPERA}

ABSTRACT: The text presented here is a new chapter of Opisanie świata, novel that I had published in 2013. It is a book that originated closely related to some researches I was developing at the time, suffering influences of several readings. One of this readings that influenced me most was Maria com Marcel, by Raul Antelo, which had an imense impact not only on the researches I was developing and I would develop later, but also on the structure of the book, due to the way Antelo dealt with some issues that were dear to me: relations between America and Europe, and emphasis on certain authors who are displaced on the oficial narratives of Brazilian Modernism, such as Raul Bopp, Flávio de Carvalho and Maria Martins. "A ópera", thus, wants to be, somehow, a ficcional essay (a critical fiction) about Raul Antelo's method.

KEYWORDS: Raul Antelo; Opisanie świata; Modernism.

Veronica Stigger é escritora, jornalista e professora da Fundação Armando Álvares Penteado e do Instituto Superior de Educação Vera Cruz. 


\section{A ÓPERA}

Veronica Stigger

No navio, não havia um teatro propriamente dito, com palco, plateia, coxia, urdimento, vara de luz, pano de boca, fosso de orquestra. Mas havia uma pequena orquestra, refletores, um salão de baile e muitas cadeiras na sala de jantar. Bopp e o senhor e a senhora Andrade não precisavam de muito mais do que isso para colocar em cena a ópera que haviam concebido dias antes, numa tarde especialmente entediante e chuvosa. O texto era do senhor Andrade, a direção, de Bopp, e os cenários e figurinos, da senhora Andrade. A música fora criada coletivamente, uma vez que nenhum deles possuía formação musical - apenas o mínimo esperado das pessoas que, como o senhor e a senhora Andrade, usufruíram de uma boa educação. Dona Oliva, que sabia entreter os convivas nas reuniões familiares dedilhando no piano num desempenho pouco acima do sofrível, ajudou-os na empreitada. Os cantores não poderiam ser outros: as Olivinhas, Hans e Curto Chivito, com participação especial de Priscila, que entraria apenas na última cena, se jogaria no chão e estremeceria todo o corpo, elevando e baixando o tronco em movimentos rápidos e compassados e batendo com os braços e as pernas no piso até desfalecer - o que indicaria o fim da ópera. A senhora Andrade desenhou, um a um, os convites para o espetáculo e os distribuiu, com a ajuda das crianças, a todos os passageiros da embarcação. No dia da estreia, não houve quem faltasse. Estavam lá a família francesa que fazia todas as refeições sem que um dirigisse a palavra ao outro, assim como a dupla de meninos loirinhos, a amiguinha deles, magra, comprida e de cabelos pretos, a vira-lata Margarida, a inglesa mirradinha de nariz arrebitado que participava ativamente das surubas na cozinha, o senhor da cadeira de rodas, sua enfermeira forte e morena, de braços e pernas grossas, o homem triste, a mulher do homem triste, sempre vestida com seu chemisier simples de algodão estampado, os jovens e robustos irmãos gêmeos alemães, o inglês roliço de meia-idade, os três italianos de terno risca de giz e brilhantina nos cabelos, o comandante, o cozinheiro, o imediato, o barbeiro, o foguista, Dona Oliva, que remexia o terço entre os dedos, nervosa com a primeira apresentação em público das sobrinhas, Opalka, que havia passado todo o dia anterior a ajudar a senhora Andrade a costurar os figurinos desenhados por ela, Netuno, Nossa Senhora do Desejo... enfim, não faltava ninguém. 
Estavam todos espremidos no comprido salão de baile - que era grande, bem grande, mas não o suficiente para conter a população inteira do navio. Bopp e o senhor Andrade dispuseram as cadeiras da sala de jantar por toda a extensão do salão, deixando livre apenas uma área de dez metros por vinte no fundo do recinto, onde comumente ficava a pequena orquestra nas poucas festas realizadas a bordo. Ali se deu a encenação da ópera. Não havia palco. Nem qualquer outro tipo de estrado ou tablado que separasse e elevasse a área da representação. Não havia também cortina e bastidor. Todos os cantores ficavam visíveis, esperando sua vez de entrar em cena. Dois refletores do navio foram colocados em cada um dos cantos da área livre, voltados, em diagonal, para o centro da cena. Bopp e a senhora Andrade estavam encarregados de movimentá-los durante a apresentação, jogando o foco de luz ora num ora noutro intérprete. E a orquestra foi toda espalhada pelas duas laterais do salão - o que não deu muito certo, porque, dada a lotação da sala, os músicos não tinham um bom espaço em torno deles, sendo inevitável a colisão involuntária com alguns dos espectadores. Vamos colocar por terra as convenções pequeno-burguesas, disse o senhor Andrade. Vamos meter os estribos na barriga da grã-finagem, acrescentou Bopp. Depois do fim do mundo: foi como os dois batizaram a ópera. A ação se desenrolava dali a cem anos, quando - eles achavam - tudo estaria acabado (a água, a comida, a Amazônia) e os poucos sobreviventes agonizariam num inferno ignorante de sua própria condição infernal. A senhora Andrade projetou um cenário futurista e opressivo, com prédios altos, completamente gradeados, da entrada às janelas. Ela queria que uma grade se emendasse à outra, como se fossem galhos de plantas menores que se enroscassem nos troncos das árvores maiores. Imaginava janelas que chegassem a ter duas grades, uma por sobre a outra, imbricadas, fundidas; grades escuras, grossas, algumas enferrujadas, outras, com grandes cadeados aparentes. A ideia era que, de longe, os prédios parecessem estar cobertos por uma imensa teia, como numa imagem de pesadelo. Esses edifícios foram fabricados com o papel que sobrara da pandorga em forma de elefante construída pelas crianças na semana anterior e com novos papéis doados pelos passageiros do navio. Sobre eles, a senhora Andrade desenhou as grades e os cadeados em perfeito trompe l'oeil. Para os figurinos, ela lançou mão de um tecido novo, preto e emborrachado, que encontrara em Paris e trazia em profusão em sua bagagem. Com ele, costurou macacões justos no corpo e toucas que deveriam cobrir completamente as cabeças das Olivinhas, de Hans e de Curto Chivito. Priscila estaria vestida de Priscila: camisa branca sem gola, de braços largos, 
com uma saia vermelha longa e rodada, enfeitada, na base, com fitas coloridas e, por cima de tudo, um avental azul-marinho. Como não havia cortina, os cantores já se encontravam no palco quando a audiência começou a entrar e a se acomodar nas cadeiras. Nem todos conseguiram se sentar. Muitos tiveram que assistir ao espetáculo de pé, em torno da porta. Hans, Curto Chivito e as Olivinhas se achavam parados, de lado para a plateia, no canto esquerdo. Priscila permaneceu bem no fundo, ao centro, de pé, encostada ao cenário, com os braços estendidos ao longo do corpo e os olhos fixos nos espectadores, quase sem piscar. Hans e Curto Chivito, vestindo os macacões pretos emborrachados e as toucas da mesma cor e tecido que lhes cobriam totalmente os cabelos, deram um passo à frente e pararam, conservando-se de lado para a plateia. Tão logo eles começaram a se movimentar, todos se puseram a aplaudir efusivamente, como se estivessem diante de Caruso e Titta Ruffo. Quando os aplausos cessaram, eles se viraram de frente para o público e se ajoelharam no chão. Nesse momento, a pequena orquestra começou a tocar. Primeiro, subiram os violinos, seguidos dos violoncelos e do contrabaixo. Hans e Curto Chivito permaneciam ajoelhados com os braços soltos ao lado do corpo. Dado que o salão de baile não tinha palco, nem qualquer outro tipo de tablado, muito menos a inclinação na plateia de que as salas de espetáculo comumente gozam, aqueles que se sentavam nas filas posteriores à terceira não conseguiam vê-los naquela posição. Assim, algumas pessoas começaram a se levantar, o que irritou as demais. Aquelas das fileiras posteriores, que se mantiveram sentadas, se botaram a assoviar em protesto, sobrepondo-se à música. As Olivinhas, igualmente vestidas com o macacão preto emborrachado e a touca da mesma cor e tecido cobrindo completamente seus cabelos, caminharam até onde estavam os dois e se puseram atrás deles, apoiando delicadamente as mãos em seus ombros. Nesse momento, subiram as flautas e os clarinetes. Em seguida, as trompas e os fagotes. O senhor Andrade, que se achava na porta de entrada do salão, no lado oposto àquele em que se dava a cena, diante da multidão que ficara em pé, se pôs a dar socos violentos no tambor que improvisou com o tonel que as crianças faziam de piscina, cuja boca cobriu com o couro do assento de três cadeiras, produzindo um som curto, seco e grave. Todos aqueles que reclamavam de não poder ver o que se passava à frente subitamente se calaram. As trompas e os fagotes cessaram e só se ouviu então o tambor que o senhor Andrade surrava com selvageria. Depois de sete batidas secas, as cordas voltaram a tocar uma melodia arrastada, que parecia não se completar nunca, lembrando muito o zumbido de um 
mosquito. Por fim, soou o fagote. Enquanto isso, as batidas do senhor Andrade sobre o tambor se tornavam cada vez mais aceleradas. De repente, a orquestra parou de tocar. Hans e Curto Chivito, ainda de joelhos, abriram as bocas para cantar. A plateia, que esperava ansiosamente esse momento, aplaudiu freneticamente. Os aplausos foram tão efusivos que ninguém percebeu, de imediato, que, emboras as bocas de Hans e Curto Chivito estivessem muito abertas, não se escutava som algum. Quando as palmas morreram, muitos espectadores se entreolharam. A plateia não ouvia nada, absolutamente nada do que eles cantavam. Alguns cochicharam com os vizinhos, para se certificar de que o problema não era pessoal. Outros coçaram os ouvidos achando que estavam entupidos. Hans e Curto Chivito pareciam não notar que as palavras que emitiam não eram audíveis. Continuavam a mexer os lábios e a fazer caretas, esforçando-se por atingir as notas mais altas. As Olivinhas também se puseram a cantar. Mas tampouco de suas bocas se percebia qualquer som. $\mathrm{Na}$ plateia, só uma pessoa conseguia ouvi-los. Sentado bem no centro da terceira fileira improvisada, de pernas cruzadas, impecavelmente vestido com seu terno estival de linho, o professor Antelo, com um sorriso no rosto, apreciava a voz grave e aveludada de Hans, o único ali com real propensão para o canto, e, enquanto o escutava entoar aquela ária que falava de como a vida seria depois da catástrofe que fizera arder a Terra, anotava mentalmente as quarenta belas páginas que escreveria sobre aquela ópera tão tosca e, ao mesmo tempo, tão comovente em sua precariedade, que nunca mais seria encenada e a qual ninguém - a não ser o professor Antelo - recordaria. 